\title{
CHANGES IN SUBFOVEAL CHOROIDAL THICKNESS BEFORE AND AFTER PANRETINAL PHOTOCOAGULATION IN PROLIFERATIVE DIABETIC RETINOPATHY USING SPECTRAL DOMAIN OPTICAL COHERENCE TOMOGRAPHY
}

By

\author{
Mohamed Selim El-Kady, Hassan Metwally Bayomy and Awab El-Sayed \\ Attia E-Sayed
}

Departments of Ophthalmology, Faculty of Medicine, Al-Azhar University

Corresponding author: Awab Elsayed Attia Elsayed,

E-Mail: awabelhefnawy91@gmail.com

\begin{abstract}
Background: Diabetic retinopathy is the third highest cause of functional vision loss in people older than 50 years. There are few measures accessible to prevent diabetic retinopathy beyond control of tight glycemic control, cessation of smoking, BP control and correction of dyslipidemia. Beyond control of systemic factors, laser photocoagulation, Intravitreal anti-VEGF drugs and Intravitreal corticosteroids are the principal therapies to reduce sight threatening DME. Laser photocoagulation and Vitreoretinal surgery are the main treatments for PDR.

Objective: We aimed to evaluate changes in SFCT before and after argon laser (PRP) in patients with PDR using spectral-domain optical coherence tomography (SD-OCT).

Patients and methods: A prospective observational clinical study on 30 eyes with proliferative diabetic retinopathy. SD-OCT was done before starting PRP, one month and three months following last session of Argon laser. All patients will undergo full medical and ophthalmic history including onset and duration of diabetes, history of ocular surgeries, laser intervention. All patients will undergo complete ophthalmic examination includes Visual acuity: Uncorrected VA (UCVA) \&best corrected VA (BCVA), Anterior segment examination using Slit-lamp biomicroscopy ,Intraocular pressure (IOP) measurement by applanation tonometry, Fundus examination ,OCT imaging using SD-OCT before starting PRP , one month and three months after last session of PRP and all patients will receive PRP using Argon laser photocoagulation.
\end{abstract}

Results: In patients with diabetic retinopathy treated by pan retinal photocoagulation there is no significant change in sub foveal choroidal thickness noticed after one month but there is a significant change after three months. Conclusion: Proliferative Diabetic Retinopathy cases treated by pan retinal photocoagulation presented by significant improvement in BCVA and there was no significant change in sub foveal choroidal thickness noticed after one month but there is a significant change after three months.

Keywords: Proliferative Diabetic Retinopathy, pan retinal photocoagulation, sub foveal choroidal thickness, spectral Domain Optical Coherence Tomography. 


\section{INTRODUCTION}

Other than retina, diabetes may affect anterior segment structures of the eye such as cornea, iris, ciliary processes and lens. Diabetic retinopathy (DR) is predominantly a microvascular disease. It affects the smaller vessels by causing multilayering of the basement membrane and degeneration of the endothelial cells and the pericytes that lead to capillary occlusion and leakage. DR is divided into two main groups namely the nonproliferative diabetic retinopathy (NPDR) and the proliferative diabetic retinopathy (PDR) (Suraida et al., 2018).

According to the Early Treatment Diabetic Retinopathy Study (ETDRS) standard classification retinopathy was considered present if any characteristic lesions as defined by the ETDRS severity grading scale were present, including microaneurysms, hemorrhages, cotton wool spots, intraretinal microvascular abnormalities, hard exudates, venous beading and new vessels (Li et al., 2018).

Choroidal thickness increased significantly as the severity worsened from mild, moderate NPDR to PDR and decreased in panretinal photocoagulation (PRP) treated eyes. The subfoveal choroid was thicker in eyes with diabetic macular edema (DME) than in those without (Kim et al., 2013).

The pivotal phase III drug trials demonstrated that binding diffusible vascular endothelial growth factor (VEGF) improves visual acuity (VA) in the majority of patients. Injections of ranibizumab and aflibercept prevent progression to PDR in many high risk eyes. Ranibizumab injections are as effective as panretinal photocoagulation at controlling the complications of PDR, while causing fewer visual side effects (Stewart, 2016).

It has been proposed that PRP improves the oxygenation of ischemic inner retinal layers by destroying some of the metabolically highly active photoreceptor cells, leading to a greater flow of oxygen from the choriocapillaris to the inner layers of the retina (Iwase et al., 2017).

Spectral domain optical coherence tomography (SD-OCT) has been recently used to examine choroidal morphology revealing an irregular shape to the choroid scleral interface. The development of enhanced depth imaging (EDI)SD-OCT has improved visualization of the choroid with high resolution cross sectional imaging enabling reliable and reproducible measurements of full choroidal thickness (Rewbury et al., 2016).

\section{PATIENTS AND METHODS}

This study was conducted in Ophthalmology Department at Al Hussein University Hospital, Faculty of Medicine, Al-Azhar University.

This study was approved by the Ethics Board of Al-Azhar University.

This was a comparative interventional study that included 30 eyes of 15 patients having PDR.

Patients were recruited from the Retina sub specialty clinic of Al-Azhar University Hospitals in the period from December, 2018 to September, 2019. OCT was done at Al-Azhar university Hospitals. Approval for the study was obtained from the hospital's ethical 
committee. All patients received a thorough explanation of the study design and aims, and were provided with written informed consent. All participants confirmed their ability to follow study instructions.

Inclusion criteria: Patients with PDR as confirmed by fundus fluorescein angiography and clear ocular media.

Exclusion criteria: Retinal detachment, intraocular inflammation, previous argon laser cessions, history of intravitreal injection of anti-VEGFs, ocular media opacity interfering with imaging.

Intervention and outcome measures: After meeting all inclusion criteria the patients were evaluated by full medical/ophthalmic history including: Onset and duration of diabetes. History of ocular surgeries, History of laser intervention, Complete ophthalmic examination including (Best corrected visual acuity, Slit lamp examination to the anterior segment, Detailed fundus examination by slit lamp biomicroscopy, Measurement of IOP using Goldmann's applanation tonometry) Fundus fluorosien angiography (FFA) was done using fundus camera Topcon (TRX-50DX) to confirm diagnosis of PDR (NVDs, NVEs) and macular edema.

\section{Spectral domain optical coherence} tomography (SD-OCT) was done to all eyes using the Optovue RTVue model RT100, Optovue, Inc., Fremont, CA). SDOCT this was done before starting PRP, one month and three months following the third laser cession. The scan pattern used on Optovue RTVue was the retina cross line which consists of two orthogonally oriented $6 \mathrm{~mm}$ lines consisting of $1024 \mathrm{~A}$ scans. The chorioretinal interface is adjacent to the zero delay. The retina cross line scan has 32 frames averaged, 16 per direction, without tracking. These scans were marked as the patient's baseline and were used for referencing the subsequent scans using the "follow-up" function of the SD-OCT, assuring us that the scans would be performed in the same position. In the horizontal and vertical macular scans, measurements of choroidal thickness were performed manually using the calipers provided by the software on the center of the fovea. Choroidal thickness was measured from the outer limit of the retinal pigment epithelium to the choroid- scleral junction. All images were taken as close to the fovea as possible in order to ensure, to the best extent possible, that the same retinal area was being scanned.

\section{Pan Retinal photocoagulation}

All patients received PRP using argon laser photocoagulator, (Zeiss VISULAS Trion). PRP was performed in a dark room approximately $30 \mathrm{~min}$ after the eye was pharmacologically dilated with $1 \%$ tropicamide. A drop of alpha agonist is installed to the eye before starting the laser cession to avoid spikes of IOP elevation. All eyes were anesthetized with topical $0.4 \%$ Benoxinate hydrochloride eye drops. Argon green laser was used with a retinal spot size of 100-300? $\mathrm{m}$ and an intensity of $200 \mathrm{mw}-500 \mathrm{mw}$ until a gray burn spot was evident. The duration of the application was $0.05-0.1 \mathrm{~s}$, and the total number of spots was approximately 2,000-2,400. Three laser cessions were done with one week apart. After each laser cession topical steroids and alpha agonist were prescribed to the patients. One month and three months after the last laser 
cession all patients were reevaluated by full history taking, ophthalmological examination including BCVA, slit lamp examination of the anterior segment, assessment of the IOP by Goldmann's applanation tonometry, detailed fundus examination by slit lamp bio microscopy and OCT were done. We compare the change of subfoveal choroidal thickness before and after PRP.

Statistical analysis: Data were analyzed using Statistical package for Social
Science (SPSS) version 15.0. Quantitative data were expressed as mean \pm standard deviation (SD). Qualitative data were expressed as frequency and percentage.

The following tests were done: Independent-samples t-test of significance was used when comparing between two means.

Pvalue $<0.05$ was considred Significant.
The mean age in studied patients was $57.2 \pm 4.4$ years with minimum age of 50 years and maximum age of 65 years (range $50-65$ ). There were 9 males $(60 \%)$ and 6 females $(40 \%)$ in studied

\section{RESULTS}

Table (1): Description of Age, Sex and disease duration in studied Patients.

\begin{tabular}{|c|c|c|c|}
\hline \multicolumn{2}{|l|}{ Variables } & \multirow{2}{*}{\multicolumn{2}{|c|}{$\begin{array}{l}\text { Studied patients }(\mathrm{N}=15) \\
57.2\end{array}$}} \\
\hline \multirow[t]{5}{*}{ Age (years) } & Mean & & \\
\hline & $\pm \mathrm{SD}$ & \multicolumn{2}{|c|}{4.4} \\
\hline & Min & \multicolumn{2}{|c|}{50} \\
\hline & $\operatorname{Max}$ & \multicolumn{2}{|l|}{65} \\
\hline & Range & \multicolumn{2}{|c|}{$(50-65)$} \\
\hline \multirow[t]{2}{*}{ Sex } & Male & 9 & $60 \%$ \\
\hline & Female & 6 & $40 \%$ \\
\hline \multirow[t]{5}{*}{ Disease duration (years) } & Mean & \multicolumn{2}{|l|}{30} \\
\hline & $\pm \mathrm{SD}$ & \multicolumn{2}{|c|}{8.7} \\
\hline & Min & \multicolumn{2}{|l|}{15} \\
\hline & Max & \multicolumn{2}{|l|}{41} \\
\hline & Range & \multicolumn{2}{|c|}{$(15-41)$} \\
\hline
\end{tabular}

Statistical significant difference was between pre-PRP and 1 month post-PRP BCVA in studied patients. BCVA was $0.41 \pm 0.04$ in pre-PRP and $0.46 \pm 0.02$ in 1 month post-PRP and 3 months post-PRP BCVA in studied patients. BCVA was $0.41 \pm 0.04$ in pre-PRP and $0.47 \pm 0.03$ in 3 months post-PRP. No statistical significant difference ( $\mathrm{p}$-value $>0.05$ ) between pre-PRP and 1 month post-PRP patients. The mean disease duration in studied patients was $30 \pm 8.7$ years with minimum duration of 15 years and maximum duration of 41 years (range 15 - 41) - (Table 1). 
and 3 months post-PRP IOP in studied patients. IOP was $(14.27 \pm 1.2)$ in prePRP, $(14.1 \pm 1.12)$ in 1 month post-PRP.

Table (2): comparison between pre-PRP, 1 Month and 3 Months post-PRP (BCVA, Sub-foveal choroidal thickness, IOP) in studied patients.

\begin{tabular}{|c|c|c|c|c|}
\hline \multicolumn{2}{|l|}{ Variables } & $\begin{array}{l}\text { Pre-PRP } \\
(\mathrm{N}=30 \text { eye })\end{array}$ & $\begin{array}{l}1 \text { month Post-PRP } \\
(\mathrm{N}=30 \text { eye })\end{array}$ & $\begin{array}{l}3 \text { month Post-PRP } \\
(\mathrm{N}=30 \text { eye })\end{array}$ \\
\hline \multirow[t]{2}{*}{ BCVA } & Mean & 0.47 & $0.42(<0.001 \mathrm{HS})$ & \multirow{2}{*}{$\begin{array}{l}0.4(<0.001 \mathrm{HS}) \\
0.03\end{array}$} \\
\hline & $\pm \mathrm{SD}$ & 0.04 & 0.02 & \\
\hline \multirow{2}{*}{$\begin{array}{l}\text { Sub-foveal } \\
\text { choroidal } \\
\text { thickness }\end{array}$} & Mean & 269.47 & $262.30(0.073 \mathrm{NS})$ & \multirow{2}{*}{$\begin{array}{l}255.93(0.003 \mathrm{~S}) \\
14.31\end{array}$} \\
\hline & $\pm \mathrm{SD}$ & 19.29 & 9.22 & \\
\hline \multirow[t]{2}{*}{ IOP } & Mean & 14.27 & $14.1(0.581 \mathrm{NS})$ & \multirow{2}{*}{$\begin{array}{l}13.97(0.297 \mathrm{NS}) \\
1.0\end{array}$} \\
\hline & $\pm \mathrm{SD}$ & 1.2 & 1.12 & \\
\hline
\end{tabular}

\section{DISCUSSION}

It is generally recommended that PRP should include more than 2000 laser applications, but there is only sparse documentation available to indicate how the treatment should be applied to optimize the positive effects and minimize the adverse effects. Relevant factors might include the number of applications and the length of the time intervals between treatment sessions. Other clinical background parameters such as visual acuity (VA) and the severity of retinopathy have been shown to predict the visual prognosis after PRP (Wong et al., 2018).

Clinicians now perform PRP using various wavelengths including argon green $(514 \mathrm{~nm})$, krypton red $(647 \mathrm{~nm})$, diode $(810 \mathrm{~nm})$, and tunable dye (560-640 $\mathrm{nm})$ lasers. Traditionally laser burns have been placed one by one in a grid pattern outside the vascular arcades, with spot size ranging from 100 to $500 \mathrm{mw}$ and pulse durations from 100 to $200 \mathrm{Ms}$. Based on the DRS, at least 1500 PRP burns are delivered using this technique. Because placing so many laser spots often
And $(13.9 \pm 1.0)$ in 3 months post-PRP (Table 2). 1.0 leads to patient discomfort and fatigue, PRP is usually performed over several sessions (Chappelow et al., 2012).

Mechanisms supposed for PRP include: Improvement of retinal oxygenation (by facilitating oxygen diffusion from the choroid), Elimination of a portion of the hypoxic retina and the vasoprolifrative factors it produces. Others have suggested that neovascularization may also be inhibited by laser-induced alteration of matrix metalloproteinase and tissue inhibitors of metalloproteinase production by the retinal pigment epithelium (Caprara and Grimm, 2012).

SD-OCT has evolved over a decade as one of the most important diagnostic tools in ophthalmology. It not only helps us in diagnosing the retinal and choroidal pathologies but also guides us in monitoring the response to treatment (Murthy et al., 2016).

Imaging the choroid with conventional commercial spectral-domain optical coherence tomography (SD-OCT) has been difficult, mainly because of difficulty in signal transmission beyond the retinal 
pigment epithelium. A recent modification to the standard technique, termed enhanced depth imaging optical coherence tomography (EDI-OCT), was able to image the choroid with reasonable clarity using commercial SD-OCT (Wong et al., 2011).

The aim of this work was to evaluate changes in subfoveal choroidal thickness (SFCT) before and after argon laser panretinal photocoagulation (PRP) as treatment in patients with proliferative diabetic retinopathy using optical coherence tomography(OCT). The results of our study showed that the mean BCVA showed statistical significant change one month and three months after the third PRP cession BCVA changed from $0.41 \pm$ 0.04 to $(0.46 \pm 0.02)$ one month after argon Pan Retinal Photocoagulation, and changed after three months to $0.47 \pm 0.03$.

The results of our study show that the mean subfoveal choroidal thickness has no statistical significant difference between pre-PRP and 1 month post-PRP subfoveal choroidal thickness in studied patients. Subfoveal choroidal thickness was $269.47 ? \mathrm{~m} \pm 19.29 ? \mathrm{~m}$ in pre-PRP, and $262.3 ? \mathrm{~m} \pm 9.22 ? \mathrm{~m}$ after 1 month post-PRP. After three months, there was a statistical significant change. Subfoveal choroidal thickness was $269.47 ? \mathrm{~m} \pm$ $19.29 ? \mathrm{~m}$ in pre-PRP and $255.93 ? \mathrm{~m} \pm$ 14.31 ? $\mathrm{m}$ after 3 months post-PRP.

Zhang et al. (2015) reported that choroidal thickness decreases 12 weeks after PRP, suggesting that PRP may reduce choroidal vascular permeability or cause atrophy of choroidal vessels over a 12 -week period. The mean SFCT at baseline was $309 \pm 77 ? \mathrm{~m}$, changing to $323 \pm 78 ? \mathrm{~m}, 315 \pm 75 ? \mathrm{~m}, 299 \pm 68 ? \mathrm{~m}$, and $289 \pm 71 ? \mathrm{~m}$ at $1,4,8$, and 12 weeks, respectively. This constituted a statistically significant increase at 1 week and a significant decrease at 12 weeks. The mean baseline CMT was $294 \pm 92$ $? \mathrm{~m}$, which increased significantly 1 week after PRP to $344 \pm 123 ? \mathrm{~m}$, remaining higher at 4 weeks $(340 \pm 117 ? \mathrm{~m})$ and 8 weeks $(318 \pm 100 ? \mathrm{~m})$, but subsiding to baseline at 12 weeks $(311 \pm 96 ? \mathrm{~m})$.

Zhang et al. (2015) presented three hypotheses regarding the observed decreases in choroidal thickness:

1. Thermal damage by photocoagulation spreads to the choroid which consequently interferes with choroidal reperfusion or reorganization, and results in a reduction in SFCT.

2. PRP damages the RPE and decreases VEGF secretion which results in decreased dilation and permeability of the choroidal vessels.

3. The outer retina is destroyed and the hypoxic inner retina comes closer to the highly saturated choriocapillaris, which then improves the hypoxic state. Autoregulation decreases the choroidal blood flow and causes a decrease in SFCT.

Ohara et al. (2018) reported that SFCT significantly decreased after PRP, which continued for 6 months after treatment. The SFCT before PRP treatment was $268.6 \pm 104.5 \mu \mathrm{m}$ (mean \pm standard deviation) and was significantly decreased at 1,3 , and 6 months after PRP $254.5 \pm$ $105.3,254.2 \pm 108.2$, and $248.1 \pm 101.8$ $\mu \mathrm{m}$, respectively.

Roohipoor et al. (2016) showed that Subfoveal CT significantly decreased at 10 months compared with baseline in the 
PRP group $(320.8 \pm 57.7) ? \mathrm{~m}$ at baseline to $(297 \pm 66.3) ? \mathrm{~m}$ at 10 months, $\mathrm{P}=$ $0.01)$. The best-corrected visual acuity did not change after treatment, and there was no correlation between BCVA and choroidal thickness.

Okamoto et al. (2016) report that the mean subfoveal choroidal thickness was reduced significantly from (327.4) ?m at the baseline to (286.3) ? $\mathrm{m}$ at 1 month and (285) ? $\mathrm{m}$ at 3 months after PRP. After PRP, the best-corrected visual acuity, intraocular pressure, and $\mathrm{HbAlc}$ did not change significantly.

On the other hand, our study disagreed with a study conducted by Cho et al. (2013) which showed that PRP induced increases in both SFCT , SFCT before PRP was (318.1 \pm 96.5$) ? \mathrm{~m}$ and increased to (349.9 \pm 108.3$) ? \mathrm{~m}(\mathrm{P}=0.001)$ after PRP.

\section{CONCLUSION}

Proliferative Diabetic Retinopathy
cases treated by pan retinal
photocoagulation presented by significant
improvement in BCVA, NO significant
change in sub foveal choroidal thickness
noticed after one month but there is a
significant change after three months and
I.O.P. had no significant change.

\section{REFERENCES}

1. Caprara, C. and Grimm, C. (2012): From oxygen to erythropoietin: relevance of hypoxia for retinal development, health and disease. Progress in retinal and eye research, 31(1): 89-119.

2. Chappelow, A. V., Tan, K., Waheed, N. K. and Kaiser, P. K. (2012): Panretinal photocoagulation for proliferative diabetic retinopathy: pattern scan laser versus argon laser. American Journal of Ophthalmology, 153(1): 137-142.
3. Iwase, T., Kobayashi, M., Yamamoto, K., Ra, E. and Terasaki, H. (2017): Effects of photocoagulation on ocular blood flow in patients with severe non-proliferative diabetic retinopathy. PloS one, 12(3): e0174427.

4. Kim, J. T., Lee, D. H., Joe, S. G., Kim, J. G. and Yoon, Y. H. (2013): Changes in choroidal thickness in relation to the severity of retinopathy and macular edema in type 2 diabetic patients. Investigative Ophthalmology \& Visual Science, 54(5): 3378-3384.

5. Li, Y. Y., Yang, X. F., Gu, H., Snellingen, T., Liu, X. P. and Liu, N. P. (2018): The relationship between insulin resistance/ $\beta$-cell dysfunction and diabetic retinopathy in Chinese patients with type 2 diabetes mellitus: the Desheng Diabetic Eye Study. International Journal of Ophthalmology, 11(3):493-497.

6. Murthy, R. K., Haji, S., Sambhav, K., Grover, S. and Chalam, K. V. (2016): Clinical applications of spectral domain optical coherence tomography in retinal diseases. Biomedical journal, 39(2): 107-120.

7. Ohara, Z., Tabuchi, H., Nakakura, S., Yoshizumi, Y., Sumino, H., Maeda, Y. and Kiuchi, Y. (2018): Changes in choroidal thickness in patients with diabetic retinopathy. International Ophthalmology, 38(1): 279-286.

8. Okamoto, M., Matsuura, T. and Ogata, N. (2016): Effects of panretinal photocoagulation on choroidal thickness and choroidal blood flow in patients with severe nonproliferative diabetic retinopathy. Retina, 36(4): 805-811

9. Rewbury, R., Want, A., Varughese, R. and Chong, V. (2016): Subfoveal choroidal thickness in patients with diabetic retinopathy and diabetic macular edema. Eye, 30(12):1568-1572.

10. Roohipoor, R., Sharifian, E., Ghassemi, F., Riazi-Esfahani, M., Karkhaneh, R., Fard, M. A. and Moghimi, S. (2016): Choroidal thickness changes in proliferative diabetic retinopathy treated with panretinal photocoagulation versus panretinal 
photocoagulation with intravitreal bevacizumab. Retina, 36(10): 1997-2005.

11. Stewart MW (2016): Treatment of diabetic retinopathy: recent advances and unresolved challenges. World journal of diabetes, 7(16): 333-339.

12. Suraida AR, Ibrahim $M$ and Zunaina $E$ (2018): Correlation of the anterior ocular segment biometry with HbA1c level in type 2 diabetes mellitus patients. PloS one, 13(1): e0191134.

13. Wong IY, Koizumi $H$ and Lai WW (2011): Enhanced depth imaging optical coherence tomography. Ophthalmic Surgery, Lasers and Imaging Retina, 42(4): S75-S84.
14. Wong, T. Y., Sun, J., Kawasaki, R., Ruamviboonsuk, P., Gupta, N., Lansingh, V. C. and Resnikoff, S. (2018): Guidelines on diabetic eye care: the International Council of Ophthalmology Recommendations for screening, follow-up, referral, and treatment based on resource settings. Ophthalmology, 125(10): 16081622.

15. Zhang, Z., Meng, X., Wu, Z., Zou, W., Zhang, J., Zhu, D. and Zhang, Q. (2015): Changes in choroidal thickness after panretinal photocoagulation for diabetic retinopathy: a 12-week longitudinal study. Investigative ophthalmology \& visual science, 56(4): 2631-2638. 


\section{التغير في سملك المشيمية تحث مركز الإبصسار قبل وبعداستخدام الليزر الكلي للثبكية في حالات اعتلال الثبكية مرينة السكري التكاثر بي باستخدام جهاز الأثعة الضوئية المقطعية المتر ابطة ذات المجال الطبني}

محمد سليم محمد القاضي، حسن متولي بيومي، أواب السيد عطيه السيد قسم طب وجراحة العيون، كلية الطب، جامعة الأزهر

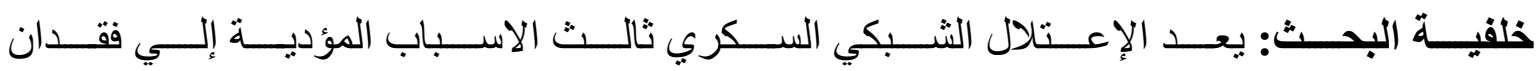

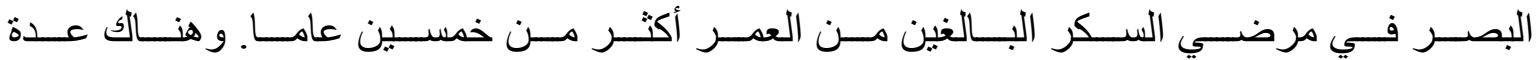

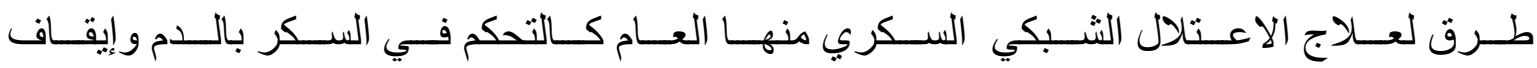

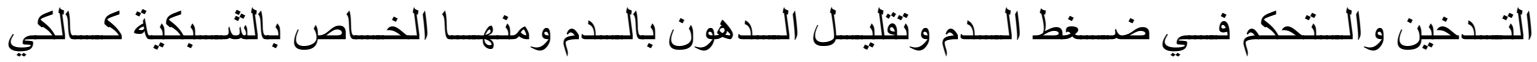

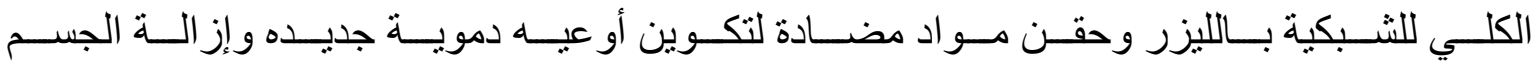
الزجاجي.

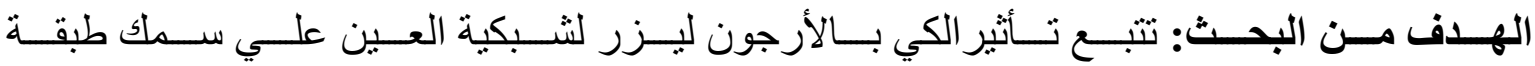
المشيمية تحت مركز الإبصار في مرضي اعتلال الثبكية السكري.

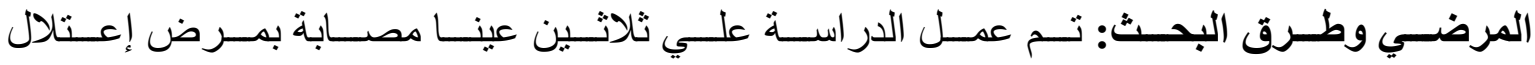

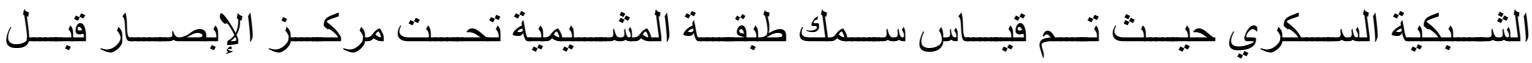

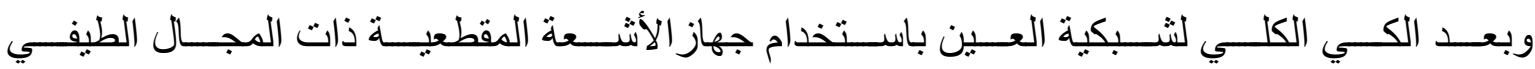

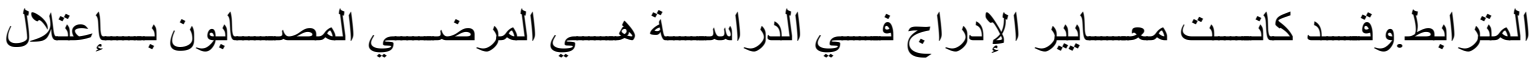

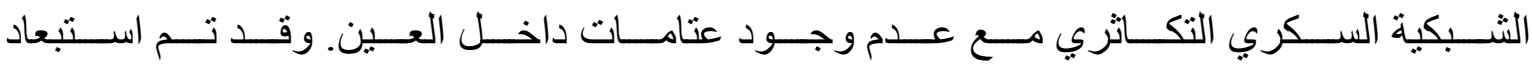

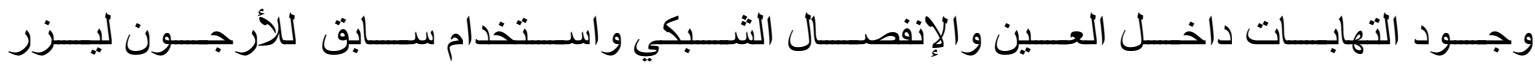

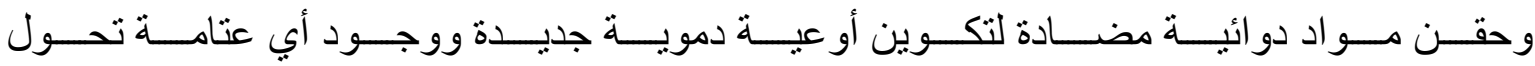

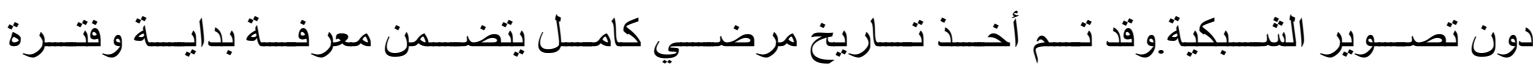

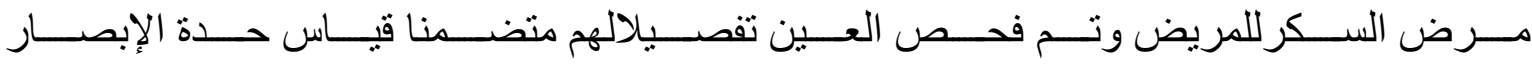

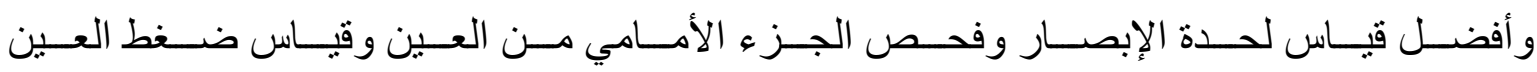

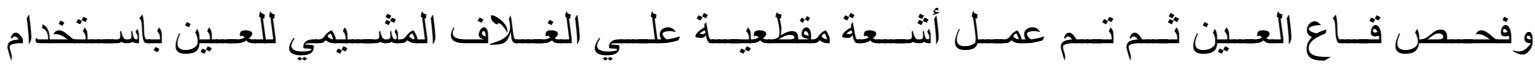

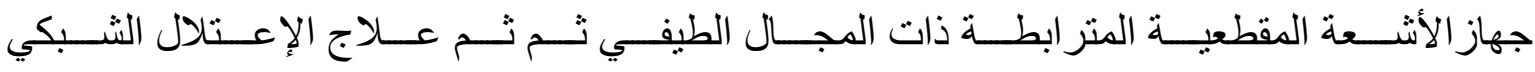




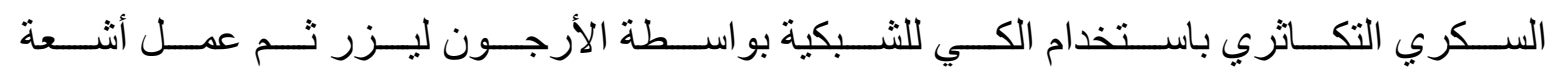

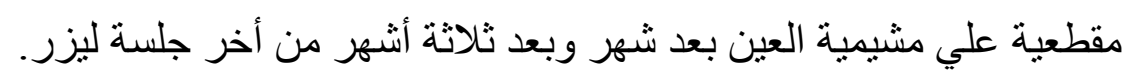

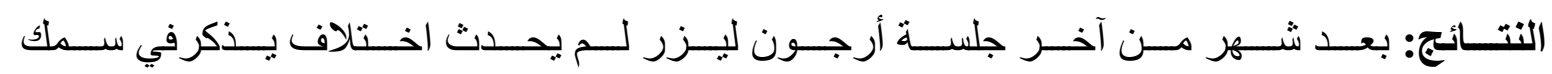

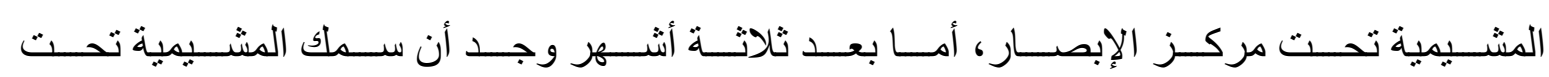

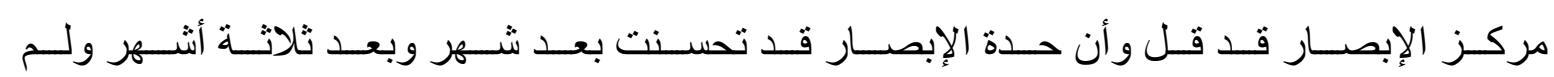
يحدث أي تغير يذكر في ضغط الإنين.

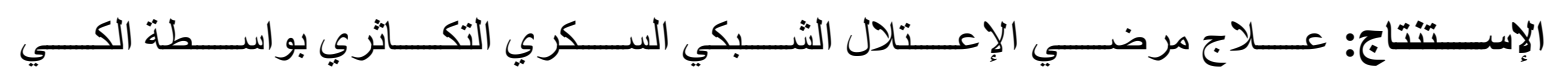

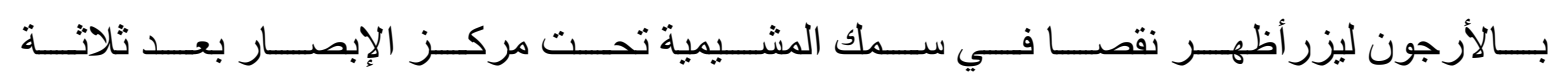

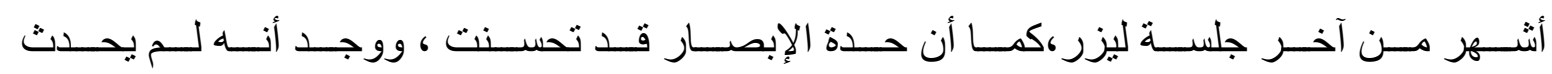
تغيير في ضغط العين. 